\title{
EDITORIAL
}

Originally this third number of Volume $12-1978$, was to have been devoted to the Proceedings of the symposium 3 held in conjunction with the Annual General Meeting, 'R Exercise - a prescription for health?'. An unfortunate $\stackrel{\mathbb{D}}{\mathscr{Q}}$ combination of circumstances, - technical difficulties over the transcription of tape recordings, a secretary heavily overloaded with a backlog of work, and the absence overseas of most of the speakers, has led to postponement of 0 publication for a short time. The symposium seemed successful; far more successful, and covering a much wider field $\overline{0}$ than was reported in many daily and weekly newpapers, or by a few snatches of a lengthy television interview taken out $\bar{E}$ of context and made to have an opposite effect to the points the speaker made. To anyone attending the symposium, $\stackrel{\infty}{\Rightarrow}$ this was a dreadful bit of mal-editing to produce sensationalism. The speaker interviewed, Dr. Dan Tunstall Pedoe, $\mathbb{D}$ wrote to the Editor of the British Medical Journal to clarify the situation, and the Editor has courteously given his $\cong$ consent to the reprinting of the letter in this issue. Although it is our editorial policy not to reprint articles published in other journals, we feel that this mis-quotation, and some biased newspaper reports are harmful to our Association, and. it is necessary to correct misinterpretation, and to warn other members of what 'the Media' can do to interviews, where $\overrightarrow{\vec{\omega}}$ the speaker is unable to check a manuscript before it is edited and printed. Because this is the policy of this journal, $\mathcal{\sigma}^{\circ}$ there is a hold-up in the Proceedings, as we are waiting for the speakers to check our transcriptions of their $\frac{\partial}{n}$. communications before we sent the manuscript to the printer, and they will also be sent proofs for a final check.

Our December number should be a large one, as we are using it as a special celebration issue to market B.A.S.M.'s twenty five years as a membership body, although a steering committee was formed a year before. We have already received some contributions from members of the Editorial Board, and hope that others are following soon.

\section{DOPING IN SPORT}

We are pleased to learn of the formation of the Drug Control and Teaching Centre, newly established at Chelsea College, University of London. Although the unit will deal with drug abuse in many fields of medicine, parts of its work will be concerned with dope detection in sportsmen, and the Sports Council are to give an annual grant towards this aspect of the project. Dope detection, especially the most difficult field of anabolic steroids, is a subject that has occupied much of the interest of B.A.S.M. over many years, but it has taken a major publicity item such as a membeo of a United Kingdom football team at a World Cup to bring it into focus. A circular letter received at the surgery from Dr. A. J. Cooper, Medical Director of Messrs E. Merck Ltd, the makers of 'Reactivan', points out that its ingredient: fencamfamin, is not an amphetamine derivative, has a different pharmacological profile, and although scheduled as Prescription only, is not a Controlled Drug. If used by a sportsman, however, it must have been prescribed for someone, by a doctor, or acquired illegally by theft or fraud. Its therapeutic use is for the symtomatic relief of debility, fatigue and apathy WHERE THERE ARE DEFINITE MEDICAL INDICATIONS, and the manufacturers have never even $\approx$

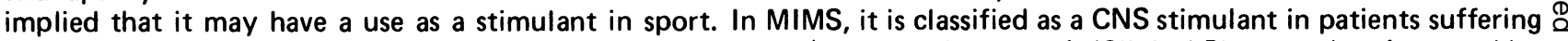
from mental and physical fatigue, and in convalescence; $£ 3.00 / 100$ tabs. Lawrence's 'Clinical Pharmacology', quoted by $\overrightarrow{\overrightarrow{0}}$ S. G. Darling of Birmingham in 'World Medicine' July 12, states it 'enhances the performance of sleep-deprived healthy 3 volunteers offered money bonuses for good performance of boring tasks'. Watching televised excerpts from other $\supset$ matches in the series, Dr. Darling could find no evidence of Reactivan doping in anyone else!

\section{F.I.M.S.}

The International Federation of Sports Medicine are holding the World Congress of Sports Medicine in Brazilia early in September. Your Treasurer/Editor has been asked to act as the official National Delegate for the United Kingdom National Body, the B.A.S.M., and to represent your Association at the Council of Delegates, and any other business $ᄋ$ meetings if required. There has been some diversion of views between B.A.S.M. and F.I.M.S. in the past few years, but $₹$ it is to be hoped that most of these will be resolved amicably. As can be seen from the Secretary's Column in the last $\frac{\text { O }}{3}$ issue of B.J.S.M., one main area of disagreement relates to the role in sports medicine of those holding qualifications in $D$ exercise physiology, physiotherapy, pharmacology and sports science, but not in medicine itself. We have been asked officially by F.I.M.S. to clarify the qualifications for the various grades of membership.

Full membership (formerly 'membre appele') are 'individuals of established specialised expertise in sports medicine. $N$ They are elected by the Executive Committee upon the recommendation of their National Association, or of the Executive Committee itself'. Eight members of B.A.S.M. are full members, six of whom are doctors.

Associate members (formerly 'fellows'), 'is granted upon request to Physicians who are members of their country's National Association, if there is one, and who have taken a national or international course of Sports Medicine ? approved by F.I.M.S.' 
A proposal is to be discussed in Brazil to establish a new grade of non-medical Collegiate members, who display an appropriate degree of involvement in sports medicine and meet the required academic standard, in a similar way to those entitled to apply for associate membership.

Whether the B.A.S.M. should also have an extension to the several grades of membership it has already; Honorary, Ordinary, Joint, Student, Retired and Affiliated, is a matter for discussion at a later date. If grades of membership for consultants, for general practitioners, for junior doctors, for physiotherapists, for sports scientists with PhD, without $\mathrm{PhD}$, etc, are to abound, it will make the administration of the Association very difficult, with an inevitable even more complicated scale of subscriptions. On the other hand, a powerful medical academic lobby might be of great use in projecting sports medicine among the Royal Colleges and Ministries. This viewpoint has been propounded in a column towards the end of this journal by Dr. John Williams, formerly our Honorary Secretary, and now Secretary General of F.I.M.S. He issues this Challenge in his private capacity, as an ordinary member of B.A.S.M. but one who holds our Association in high esteem, and has devoted many years to its promotion.

\section{CURRENT NUMBER}

Besides 'Challenge' we have another new feature in the Bulletin section. In the last issue, it was suggested that, as a result of the meeting of the Editorial Board, a section of the Journal could be devoted to Abstracts of recent relevant published work. From the National Documentation Centre for Sport at the University of Birmingham we received a list of recent publications in the English language relevant to clinical and physiological aspects of sports medicine. If members find this type of service useful, the idea can be extended.

The use of $\beta$-blockers in the treatment of hypertension and cardiac arrythmias has been extensive in cardiological and general practice. These drugs, in small doses, have also been used to steady down actors and musicians with 'first-night nerves'. Our first article is a report of the experimental use of a $\beta$-blocker during rock-climbing, where tachycardia appears to be due to psychological factors more than to exercise stress. It would seem unlikely to be of any help in competitive events, except perhaps shooting, where it could definitely be regarded as doping.

Osteitis pubis in athletes has been described by several authors in the past few years, especially in reports from the colder parts of Europe. The possibility of secondary hip joint involvement has been raised by Dr. John Wiliams in the second article. This is followed by a description of a technique for the rapid monitoring of the ECG in athletes or patients in rehabilitation units, by Morris and Dotson, of the University of Maryland, and a case study of a water-skiing injury to the brachial plexus from the Royal Collage of Surgeons of Ireland, by Moira O'Brien and her co-workers.

\section{SPORTS MEDICINE DEVELOPMENTS IN BRITAIN}

Within the past two years there has been an increasing awareness of the need to understand the training, the health and the injuries that involve sportsmen. Many different bodies are holding meetings in which sports medicine is a theme. The British Medical Journal's columnist who writes 'Medicine and the Media' classes the recent symposium on sporting injuries, held on July 11 th during the annual B.M.A. meeting at Cardiff as 'the best B.M.A. scientific meeting I ever attended', and he makes a plea for doctors to publicise the growing number of non-accidental injuries that occur, and to seek better protection without emasculating sport. Dr. J.P.R. Williams classified some matches as being 'gladiatorial combat' making him wonder if the game is worth continuing because of deliberate and dangerous fouls. The British Student Health Association are devoting the morning of their annual meeting to sports injuries in general and the afternoon to mountaineering medicine. Sports medicine is a frequent theme for meetings of branches and special interest groups of the Chartered Society of Physiotherapy, forthe Society of Remedial Gymnasts, and other paramedical organisations. Several new sports clinics have sprung up in various places that we have heard about and probably several more about whose presence and staffing we are unaware. As we have had some four hundred additions and corrections to our membership list, and as major revisions may soon have to be made to the Constitution of B.A.S.M., this might be an opportunity to invite those who are running sports medicine clinics, within the NH.S. or outside it, to send us details so that we might compile a register which would give the names and qualifications of its staff, eligible patients, back-up facilities such as X-Ray, physiotherapy, surgery etc., hours of work, and cost to patients or clubs.

A University Medical Centre sports injuries clinic is being established at Manchester University at present restricted to their own students. A private clinic has been established in Nottingham by Dr. M. A. Hutson, with Mrs. Pamela Marsh, MCSP, in daily attendance (Nottingham 44755). In the last journal we announced a clinic supported by the Institute of Sports Medicine had been founded at the Addenbrooke's Hospital, Cambridge, directed by Dr. Sylvia Lachmann. We now hear that Cambridge is to have a sports injuries clinic run in connection with the City's Sports Centre, and directed by Mr. B. F. Meggitt, FRCS, Consultant Orthopaedic Surgeon, the Addenbrooke's Hospital. 
The establishment of sports clinics again raises several points about their scope of work, their medical direction, and the training of their medical and ancillary staff. With changes contemplated in the ethical conduct of physiotherapists, no longer bound to take patients that have first to be referred by a doctor, should there have to be medical direction? Should medical directors of such clinics be required to sit an examination in the theory and practice of sports medicine and gain a diploma? Should such a diploma be instituted? By whom? Who will examine candidates? Should clinics be run only by consultants experienced in trauma? Should consultant cover be available, even if registrars and clinical assistants actually see most of the patients? Should patients be taken only if referred by their GP? Only accepted if of recognised standard? Should they first be screened by the Casualty Officer or Orthopaedic Surgeon? Should there be open access, as in accident and emergency or venereology departments? Should club secretaries or team coaches be able to refer patients? Above all, WHO PROVIDES THE MONEY FOR THE BUILDING, ITS RUNNING COSTS, AND ITS STAFF?

Answers to some of these questions might be produced by the Sports Council's new sub-committee, set up on the suggestion of the Minister, Mr. Denis Howell, and with our Honorary Secretary, Dr. Peter Sperryn, as its chairman.

H. E. Robson.

NOTE ADDED IN PROOF

INTERNATIONAL DOPING CONTROL

We understand that the Sports Council have offered £25,250 towards the setting up of an International doping Control organisation, and that this offer has been made at a meeting of the International Amateur Athetlics Board held in Puerto Rico. 